\title{
The role of SEF14 and SEF17 fimbriae in the adherence of Salmonella enterica serotype Enteritidis to inanimate surfaces
}

\author{
MARTIN J. WOODWARD, MARCJANNA SOJKA, KATHERINE A. SPRIGINGS and TOM J. \\ HUMPHREY*
}

Department of Bacteriology, Veterinary Laboratories Agency (Weybridge), Woodham Lane, New Haw, Addlestone, Surrey KT15 3NB and *Food Microbiology Research Unit, Public Health Laboratory Service, Church Lane, Heavitree, Exeter EX2 5AD

To gain an understanding of the role of fimbriae and flagella in the adherence of Salmonella enterica serotype Enteritidis to inanimate surfaces, the extent of adherence of viable wild-type strains to a polystyrene microtitration plate was determined by a crystal violet staining assay. Elaboration of surface antigens by adherent bacteria was assayed by fimbriae- and flagella-specific ELISAs. Wild-type Enteritidis strains adhered well at $37^{\circ} \mathrm{C}$ and $25^{\circ} \mathrm{C}$ when grown in microtitration wells in Colonisation Factor Antigen broth, but not in other media tested. At $37^{\circ} \mathrm{C}$, adherent bacteria elaborated copious quantities of SEF14 fimbrial antigen, whereas at $25^{\circ} \mathrm{C}$ adherent bacteria elaborated copious quantities of SEF17 fimbrial antigen. Non-fimbriate and non-flagellate knock-out mutant strains were also assessed in the adherence assay. Mutant strains unable to elaborate SEF14 and SEF17 fimbriae adhered poorly at $37^{\circ} \mathrm{C}$ and $25^{\circ} \mathrm{C}$, respectively, but adherence was not abolished. Non-motile mutant strains showed reduced adherence whilst type-1, PEF and LPF fimbriae appeared not to contribute to adherence in this assay. These data indicate that SEF17 and SEF14 fimbriae mediate bacterial cell aggregation on inanimate surfaces under appropriate growth conditions.

\section{Introduction}

Salmonella enterica serotype Enteritidis is a major cause of food-borne infection of man, with poultry and poultry products cited as common sources [1,2]. The occurrence of human infection indicates that serotype Enteritidis is environmentally robust and readily transmitted through the food chain. Contamination of animate and inanimate surfaces is probably an important factor in the transmissibility of this and other food-borne pathogens [3,4]. Bacterial surface hydrophobicity, charge, cell density and exopolysaccharides have been cited as important factors for adherence to surfaces; the role of other surface structures, such as flagella and fimbriae, has been considered equivocal $[5,6]$. Indeed, conflicting evidence regarding flagella and type- 1 fimbriae has arisen from studies of the adherence of serotype Typhimurium strains to chicken skin [7-9]. Recent reports indicate

Received 8 June 1999; revised version received 1 Oct. 1999; accepted 9 Nov. 1999.

Corresponding author: Professor M. J. Woodward (e-mail: mwoodward.cvl.wood@gtnet.gov.uk). that type-1 fimbriae and flagella mediate non-specific adherence of Typhimurium to mineral particles and glass [10,11]. SEF17 and type-1 fimbriae also contribute to the adherence of Enteritidis strains to stainless steel and Teflon [12]. Adherence to glass has been associated with the virulence potential of Enteritidis strains, although the contribution of fimbriae and flagella in that model was unclear [13]. SEF17 is an orthologue of the curli fimbriae of Escherichia coli. The elegant studies of Vidal et al. [14] showed that curli fimbriae were involved in adherence to glass and polystyrene, a finding which supports evidence for their role in adherence to inanimate surfaces.

Serotype Typhimurium possesses the ability to elaborate at least four kinds of fimbriae including type 1, plasmid encoded (PEF), long polar (LPF) and a curli orthologue. Each of these has been implicated in pathogenesis in mouse and chick models [15-17]. In addition, Enteritidis elaborates SEF14 fimbriae which are restricted to a number of serotypes in O serogroup D, notably serotype Dublin [18-20]. However, the role of Enteritidis fimbriae in poultry infection is equivocal [21,22], although SEF14 fimbriae may contribute to 
tropism towards reproductive tissues [23]. Detailed analysis of the environmental signals required for the expression of Enteritidis fimbriae were reported previously [24-27]. SEF14 fimbriae were elaborated at $37^{\circ} \mathrm{C}$, but not at ambient temperatures, when grown on media of low osmolarity [26] and their elaboration was enhanced by growth on agar surfaces. That observation prompted the hypothesis that surface contact was an environmental signal for SEF14 regulation [27]. SEF17 fimbriae were elaborated copiously at ambient temperatures, but not at $37^{\circ} \mathrm{C}$, when grown on low osmotic, and nutritionally poor, media. SEF17 fimbriae have been implicated in adherence to inanimate surfaces [12].

Earlier research into the role of flagella and fimbriae in the biology of serotype Enteritidis has generated defined non-fimbriate and non-flagellate mutant strains, as well as immunological reagents specific for these surface antigens $[18,19,21,22,24-27]$. The use of these resources to study the roles of fimbriae and flagella of Enteritidis in adherence to inanimate surfaces is reported in this study.

\section{Materials and methods}

\section{Bacterial strains}

Enteritidis strains are listed in Table 1. Strains 27655R and $27655 \mathrm{~S}$ were kind gifts from Professor T. Wadstrom, Sweden and wild-type strains were from the Reference Laboratories at VLA (Weybridge) and
FMRU, PHLS, Exeter. Wild-type strains of Enteritidis were stored on Dorset's egg slopes at ambient temperature. Mutant strains of Enteritidis designated EAV and strain B214 were constructed previously [19, 21], and strains designated KAS were constructed in this study. Mutant strains were stored frozen at $-70^{\circ} \mathrm{C}$ in Luria-Bertani (LB) broth supplemented with glycerol $15 \% \mathrm{w} / \mathrm{v}$.

\section{Media}

Media for the culture of wild-type and mutant strains of Enteritidis were Colonisation Factor Antigen (CFA) broth, Heart Infusion Broth (HIB), Luria-Bertani (LB) broth, LB supplemented with glucose $0.25 \% \mathrm{w} / \mathrm{v}$ (LBG), and M9 glucose $0.25 \% \mathrm{w} / \mathrm{v}$ minimal salts medium (MM) broth, or solidified with agar $1.2 \% \mathrm{w} / \mathrm{v}$ as appropriate, with growth overnight at $25^{\circ} \mathrm{C}$ and $37^{\circ} \mathrm{C}$. LBG agar was used for the selection of transductants. Antibiotics were added as required at appropriate concentrations [19,21].

\section{Culture conditions for adherence assays}

Seed cultures were prepared by picking single, wellisolated colonies from fresh LB agar streak plates into $10-\mathrm{ml}$ volumes of broth. The cultures were incubated overnight, statically at $25^{\circ} \mathrm{C}$ or $37^{\circ} \mathrm{C}$ as required, and were diluted in the same pre-warmed medium to give an optical density of 0.2 at $550 \mathrm{~nm}$. 30- $\mu$ l volumes were added to each of eight wells in a 96-well microtitration plate. A further $100 \mu \mathrm{l}$ of the same

Table 1. Wild type and mutant strains of Enteritidis used in this study

\begin{tabular}{|c|c|c|}
\hline Strain & $\begin{array}{l}\text { Mutant } \\
\text { designation }\end{array}$ & Genotype or comment \\
\hline S1400 & & Wild-type PT4 \\
\hline LA5 & & Wild-type PT4 \\
\hline $27655 \mathrm{R}$ & & Wild-type, constitutive for SEF17 \\
\hline $27655 \mathrm{~S}$ & & Wild-type, SEF17 non-expression \\
\hline I & & Wild-type non-invasive PT4 \\
\hline $\mathrm{E}$ & & Wild-type invasive PT4 \\
\hline C6B & & Wild-type invasive PT4 \\
\hline $10360 / 91$ & & Wild-type PT4 \\
\hline $278 / 95$ & & Wild-type PT4 \\
\hline $842 / 95$ & & Wild-type PT4 \\
\hline $486 / 86$ & & Wild-type PT4 \\
\hline $483 / 95$ & & Wild-type PT4 \\
\hline LA5 & B214 & sefA::kan \\
\hline LA5 & EAV3 & fim D::tet \\
\hline LA5 & EAV6 & pefC::zeo \\
\hline LA5 & EAV8 & lpfC::trim \\
\hline LA5 & EAV10 & fliC::cam \\
\hline LA5 & EAV12 & $\operatorname{agfA}:$ bla \\
\hline LA5 & EAV46 & mot $\mathrm{AB}:$ :cam \\
\hline S1400 & EAV13 & sefA::kan \\
\hline $27655 \mathrm{R}$ & EAV28 & sefA::kan \\
\hline $27655 S$ & KAS12 & sefA::kan \\
\hline LA5 & EAV38 & sefA::kan fimD::tet agfA::bla lpfC::trim pefC::zeo fliC::cam \\
\hline LA5 & EAV71 & fimD::tet sefA::kan agfA::bla pefC::zeo lpfC::trim mot $\mathrm{AB}::$ cam \\
\hline $27655 \mathrm{R}$ & KAS13 & agfA::bla sefA::kan \\
\hline LA5 & KAS14 & agfA::bla sefA::kan \\
\hline S1400 & KAS15 & agf $A:$ :bla sefA::kan \\
\hline
\end{tabular}


medium, pre-warmed to $25^{\circ} \mathrm{C}$ or $37^{\circ} \mathrm{C}$ as required, were added to each inoculated well. Loaded microtitration plates were incubated statically at $25^{\circ} \mathrm{C}$ or $37^{\circ} \mathrm{C}$ for 24 or $48 \mathrm{~h}$, as required. Three different kinds of 96-well microtitration plates were used: Falcon vinyl plates, Nunclone polystyrene flat-bottomed well plates and Nunc polystyrene round-bottomed well plates. Adherence of bacteria was assessed by crystal violet binding and protein assays (see below).

Nunclone polystyrene 24-well plates were used for cell recovery and ELISA tests (see below) of adherent bacteria. Essentially the procedures were as described above except that $100-\mu 1$ of diluted seed culture were inoculated into wells containing $1 \mathrm{ml}$ of pre-warmed medium. After incubation for adherence, the supernate was removed by aspiration and the wells were washed three times with phosphate-buffered saline (PBS). PBS $(0.5 \mathrm{ml})$ was added to each well and adherent bacteria were removed from the well surfaces by generating a vortex with a magnetic stirrer. The cell density of the resultant cell suspension was determined by optical density measurements at $500 \mathrm{~nm}$ and samples were assayed for fimbriae and flagella by ELISA.

\section{Crystal violet binding assays}

To assess the extent of bacterial adherence to the well surfaces, a crystal violet binding assay was done, essentially following the method of Pratt and Kolter [28]. Briefly, after incubation, supernate was aspirated and either discarded or stored frozen for subsequent use in ELISA tests (see below) where appropriate. Loosely adherent bacteria were removed by three washes with PBS (pH 7.2) and plates were inverted to dry. Each well was filled with $130 \mu \mathrm{l}$ of crystal violet $1 \% \mathrm{w} / \mathrm{v}$ solution and incubated at room temperature for $30 \mathrm{~min}$. Unbound crystal violet was removed by washing the plates under tap water and plates were inverted to dry. Alcohol: acetone (130 $\mu \mathrm{l}$; $70: 30 \mathrm{v}: \mathrm{v})$ was added to each well to release cell-bound crystal violet and after $10 \mathrm{~min}$ at room temperature, crystal violet concentration in solution was determined by optical density readings at $550 \mathrm{~nm}$.

\section{Fimbriae- and flagella-specific ELISAs}

Assays specific for SEF14, SEF17 and SEF21 fimbriae and for flagellin were performed as described previously [25-28].

\section{P22 transduction}

Defined non-fimbriate mutants in specific Enteritidis strains were constructed by P22 transduction of the appropriate genetic marker by methods described previously [21,22]. Briefly, donor P22 was grown on Enteritidis S1400 strain EAV38 (Table 1) and in each transduction experiment selection was made for the antibiotic resistance encoded by the cassette used to inactivate insertionally the target fimbrial gene. The genotype of each transductant was confirmed by Southern hybridisation and appropriate phenotypic tests $[21,22]$.

\section{Results \\ Development of the adherence assay with wild- type Enteritidis strain $\$ 1400$}

A well characterised wild-type Enteritidis strain (S1400) was used to establish if Enteritidis adhered to inanimate surfaces. In preliminary experiments, culture medium, temperature and time for association between bacteria and inanimate surface of the microtitration plate were varied. Adherence was observed both visually, in the form of microcolonies on the well bottom and at the interface between air and growth medium, and by crystal violet-binding assay when bacterial growth was in CFA broth at $25^{\circ} \mathrm{C}$ and $37^{\circ} \mathrm{C}$. The crystal violet-binding readings at $\mathrm{OD}_{550}$ after incubation for $48 \mathrm{~h}$ at $25^{\circ} \mathrm{C}$ and $37^{\circ} \mathrm{C}$ were 0.24 and 0.44 , respectively, in Falcon vinyl plates, 0.20 and 0.63 in Nunclone polystyrene flat-bottomed well plates, and 0.20 and 0.50 in Nunc polystyrene round-bottomed well plates. In repeat experiments, similar $\mathrm{OD}_{550}$ readings were obtained after incubation for $24 \mathrm{~h}$ with the earliest adherence detected at $6 \mathrm{~h}\left(\mathrm{OD}_{550}=0.12\right)$. However, growth in HIB, LB, LBG and MM at either $25^{\circ} \mathrm{C}$ or $37^{\circ} \mathrm{C}$ did not support adherence to the well surface of any of the three kinds of plate used.

\section{Adherence and fimbrial antigen elaboration of wild-type strains of Enteritidis}

To test whether the findings with strain S1400 were representative of other Enteritidis isolates, 12 wild-type strains including S1400 were assessed for adherence to Nunclone polystyrene flat-bottomed well plates by the crystal violet binding assay. All strains adhered after growth in CFA broth at $37^{\circ} \mathrm{C}$ for $48 \mathrm{~h}\left(\mathrm{OD}_{550} 0.42-\right.$ 1.24), whereas nine of 12 strains adhered after growth in CFA broth at $25^{\circ} \mathrm{C}$ for $48 \mathrm{~h}\left(\mathrm{OD}_{550} 0.24-1.55\right)$ (Table 2). Similar adherence values were achieved after $24 \mathrm{~h}$. Generally, cultures grown in HIB did not adhere $\left(\mathrm{OD}_{550}<0.05\right)$, except that two strains $(27655 \mathrm{R}$ and $842 / 95)$ adhered at both $25^{\circ} \mathrm{C}$ and $37^{\circ} \mathrm{C}\left(\mathrm{OD}_{550} 0.58\right.$ and 0.24 for strain $27655 \mathrm{R} ; 0.81$ and 1.55 for strain $842 / 95)$.

To test if there was any correlation between extent of adherence and elaboration of fimbrial antigens by Enteritidis, ELISAs specific for SEF14, SEF17 and SEF21 (type-1) fimbriae and flagellin were used to quantify the elaboration of these antigens from: bacteria grown overnight and used to seed the adherence assay plates; planktonic cells remaining in the well after incubation for $48 \mathrm{~h}$; and cells recovered from the well surface (Table 2). 
Table 2. Adherence of wild-type strains of Enteritidis to polystyrene and elaboration of fimbriae and flagella

\begin{tabular}{|c|c|c|c|c|c|c|c|c|c|c|c|c|c|c|}
\hline \multirow{3}{*}{$\begin{array}{l}\text { Strain } \\
\text { no. }\end{array}$} & \multirow{3}{*}{$\begin{array}{c}\text { Growth } \\
\text { temp } \\
\left({ }^{\circ} \mathrm{C}\right)\end{array}$} & \multirow{3}{*}{$\begin{array}{c}\text { Crystal } \\
\text { violet } \\
\text { binding* }\end{array}$} & \multicolumn{12}{|c|}{ Elaboration of surface antigens ${ }^{\dagger}$ by } \\
\hline & & & \multicolumn{4}{|c|}{ Seed cultures } & \multicolumn{4}{|c|}{ Cells in suspension } & \multicolumn{4}{|c|}{ Cells bound to surface } \\
\hline & & & SEF14 & SEF17 & SEF21 & Flag & SEF14 & SEF17 & SEF21 & Flag & SEF14 & SEF17 & SEF21 & Flag \\
\hline \multirow[t]{2}{*}{$\overline{\mathrm{S} 1400}$} & 25 & 0.24 & 0.06 & 0.20 & 1.34 & 2.06 & 0.00 & 0.06 & 1.21 & 2.00 & 0.02 & 0.03 & 0.06 & 0.27 \\
\hline & 37 & 0.44 & 1.60 & 0.08 & 1.04 & 1.95 & 2.41 & 0.26 & 0.38 & 1.42 & 1.79 & 0.04 & 0.30 & 0.21 \\
\hline \multirow[t]{2}{*}{ LA5 } & 25 & 1.44 & 0.03 & 1.04 & 0.12 & 1.46 & 0.00 & 0.29 & 0.50 & 1.36 & 0.06 & 0.28 & 0.03 & 0.49 \\
\hline & 37 & 0.65 & 1.60 & 0.68 & 0.33 & 1.69 & 1.85 & 0.14 & 0.15 & 1.07 & 1.68 & 0.00 & 0.05 & 0.18 \\
\hline \multirow[t]{2}{*}{$27655 \mathrm{R}$} & 25 & 1.11 & 0.00 & 1.93 & 1.53 & 1.78 & 0.01 & 0.46 & 0.11 & 0.41 & 0.02 & 0.55 & 0.09 & 0.39 \\
\hline & 37 & 0.78 & 0.00 & 1.81 & 1.39 & 1.61 & 0.00 & 0.04 & 0.77 & 0.10 & 0.18 & 0.68 & 0.43 & 0.30 \\
\hline \multirow[t]{2}{*}{$27655 \mathrm{~S}$} & 25 & 0.05 & 0.02 & 0.07 & 0.10 & 1.09 & 0.01 & 0.00 & 0.06 & 0.79 & 0.01 & 0.14 & 0.01 & 0.17 \\
\hline & 37 & 0.87 & 1.53 & 0.01 & 0.11 & 0.77 & 2.05 & 0.02 & 0.02 & 0.45 & 1.30 & 0.00 & 0.02 & 0.05 \\
\hline \multirow[t]{2}{*}{ I } & 25 & 0.06 & 0.02 & 0.07 & 1.01 & 1.90 & 0.10 & 0.05 & 1.23 & 2.01 & 0.00 & 0.10 & 0.09 & 0.16 \\
\hline & 37 & 0.42 & 1.68 & 0.01 & 1.37 & 1.82 & 2.45 & 0.03 & 0.40 & 0.95 & 1.76 & 0.00 & 0.36 & 0.23 \\
\hline \multirow[t]{2}{*}{$\mathrm{E}$} & 25 & 1.39 & 0.03 & 0.99 & 0.16 & 1.28 & 0.00 & 0.36 & 0.07 & 0.60 & 0.00 & 0.00 & 0.00 & 0.32 \\
\hline & 37 & 0.65 & 1.67 & 0.70 & 0.36 & 1.67 & 1.85 & 0.00 & 0.29 & 0.71 & 1.01 & 0.00 & 0.00 & 0.07 \\
\hline \multirow[t]{2}{*}{$\mathrm{C} 6 \mathrm{~B}$} & 25 & 1.11 & 0.04 & 1.16 & 0.14 & 1.00 & 0.01 & 0.19 & 0.03 & 0.34 & 0.00 & 0.05 & 0.01 & 0.54 \\
\hline & 37 & 0.58 & 1.46 & 0.34 & 0.56 & 1.81 & 2.26 & 0.04 & 0.22 & 1.00 & 1.08 & 0.00 & 0.06 & 0.29 \\
\hline \multirow[t]{2}{*}{$10360 / 91$} & 25 & 0.48 & 0.01 & 0.73 & 0.39 & 1.96 & 0.01 & 0.42 & 0.87 & 1.80 & 0.02 & 0.31 & 0.03 & 0.50 \\
\hline & 37 & 0.89 & 1.48 & 0.51 & 0.62 & 1.91 & 2.09 & 0.02 & 0.51 & 1.50 & 1.08 & 0.00 & 0.14 & 0.83 \\
\hline \multirow[t]{2}{*}{$278 / 95$} & 25 & 0.04 & 0.01 & 0.17 & 0.41 & 1.81 & 0.01 & 0.22 & 0.88 & 2.09 & 0.01 & 0.03 & 0.02 & 0.20 \\
\hline & 37 & 0.49 & 1.76 & 0.25 & 0.43 & 1.84 & 2.31 & 0.01 & 0.15 & 0.76 & 1.78 & 0.00 & 0.04 & 0.16 \\
\hline \multirow[t]{2}{*}{$842 / 95$} & 25 & 1.55 & 0.02 & 1.11 & 0.17 & 1.53 & 0.02 & 0.24 & 0.27 & 0.38 & 0.01 & 0.04 & 0.01 & 1.30 \\
\hline & 37 & 0.81 & 1.72 & 0.85 & 0.31 & 1.73 & 2.12 & 2.01 & 0.15 & 0.79 & 0.54 & 0.00 & 0.01 & 0.10 \\
\hline \multirow[t]{2}{*}{$486 / 86$} & 25 & 0.03 & 0.03 & 0.82 & 0.52 & 1.93 & 0.02 & 0.79 & 0.99 & 1.94 & 0.01 & 0.04 & 0.03 & 0.38 \\
\hline & 37 & 1.24 & 1.48 & 0.82 & 1.08 & 1.81 & 2.36 & 0.14 & 0.52 & 1.95 & 0.75 & 0.24 & 0.78 & 0.28 \\
\hline \multirow[t]{2}{*}{$483 / 95$} & 25 & 0.53 & 0.02 & 1.22 & 0.28 & 1.98 & 0.02 & 0.78 & 1.94 & 0.80 & 0.00 & 0.01 & 0.02 & 0.31 \\
\hline & 37 & 0.58 & 1.06 & 0.83 & 0.66 & 2.02 & 2.00 & 0.06 & 0.52 & 1.83 & 1.57 & 0.10 & 0.49 & 0.17 \\
\hline
\end{tabular}

*Adherence assessed by crystal violet binding assay (see Materials and methods).

${ }^{\dagger}$ Specific ELISAs used to detect fimbriae (SEF14, SEF17 and SEF21) and flagella (Flag) (see Materials and methods). 
At $37^{\circ} \mathrm{C}$, most Enteritidis strains from the seed and planktonic well cultures elaborated copious amounts of SEF14 fimbriae and flagella, but SEF17 and SEF21 fimbriae were not detected. Bacteria recovered from the polystyrene well surfaces elaborated both SEF14 fimbriae and flagella, although flagella were elaborated at reduced levels compared with seed and planktonic cells. SEF17 and SEF21 fimbriae were not detected. Both strain 27655R and strain 842/95 also elaborated high levels of SEF17 fimbriae.

At $25^{\circ} \mathrm{C}$, most Enteritidis strains from the seed and planktonic well cultures produced SEF17 and SEF21 fimbriae and flagella, whereas none of the 12 strains elaborated SEF14 fimbriae. Generally, the extent of elaboration of all four surface antigens expressed by bacteria bound to the wells was lower than for seed and planktonic cells. Strain 27655R was unusual in that it produced large amounts of SEF17 fimbriae.

\section{Adherence of mutant strains of Enteritidis defective for the elaboration of fimbriae}

Having demonstrated the presence of fimbriae and flagella on adherent bacteria, tests were done to establish if these surface antigens were essential for adherence to inanimate surfaces. Thus, mutant strains of Enteritidis S1400 and LA5 unable to elaborate fimbriae and flagella (Table 1) were assayed for adherence after incubation in CFA broth at both $25^{\circ} \mathrm{C}$ and $37^{\circ} \mathrm{C}$

In assays performed at $37^{\circ} \mathrm{C}$, mutant strains unable to elaborate SEF14 fimbriae showed reduced adherence (Fig. 1) whereas mutant strains unable to elaborate PEF, LPF, SEF17 or SEF21 fimbriae adhered as well as the progenitor wild-type strains. A fimbriate strain which formed paralysed flagella (EAV46) adhered, but less well than strains that were motile and elaborated SEF14 fimbriae. Differences in adherence between samplings after incubation for 24 and $48 \mathrm{~h}$ were not detected (data not shown).

Strains $27655 \mathrm{R}$ and $27655 \mathrm{~S}$ were adherent irrespective of the culture conditions, unlike the majority of Enteritidis wild-type strains tested in this study. Previous studies had shown that strain 27655R was constitutive for the elaboration of SEF17 fimbriae whereas strain $27655 \mathrm{~S}$, a genetically undefined derivative of strain 27655R, was unable to elaborate SEF17 fimbriae under any conditions [23, 24, 26]. Thus, to confirm that SEF14 fimbriae were essential for adherence in strains $27655 \mathrm{R}$ and $26755 \mathrm{~S}$, assays were performed as described above with sefA::kan transductants (Table 1). Strain 27655S adhered whereas strain KAS12, unable to elaborate SEF14, showed reduced adherence (Fig. 2). Strains 27655R and EAV28, unable to elaborate SEF14 fimbriae, adhered as shown by crystal violet binding values of $\mathrm{OD}_{550} 1.95$ and 1.03 at $24 \mathrm{~h}$, respectively (Fig. 2).

In assays performed at $25^{\circ} \mathrm{C}$, those mutant strains unable to elaborate SEF17 fimbriae did not adhere (Fig. 1), whereas mutant strains unable to elaborate PEF, LPF, SEF14 or SEF21 fimbriae adhered as well as the progenitor wild-type strains. A fimbriate strain that formed paralysed flagella (EAV46) adhered, but less well than strains that were motile and elaborated SEF17 fimbriae. Differences in the adherence between samplings after incubation for 24 and $48 \mathrm{~h}$ were not detected (data not shown). Strain 27655R adhered whereas KAS13, unable to elaborate both SEF14 and SEF17 fimbriae, did not (Fig. 2).

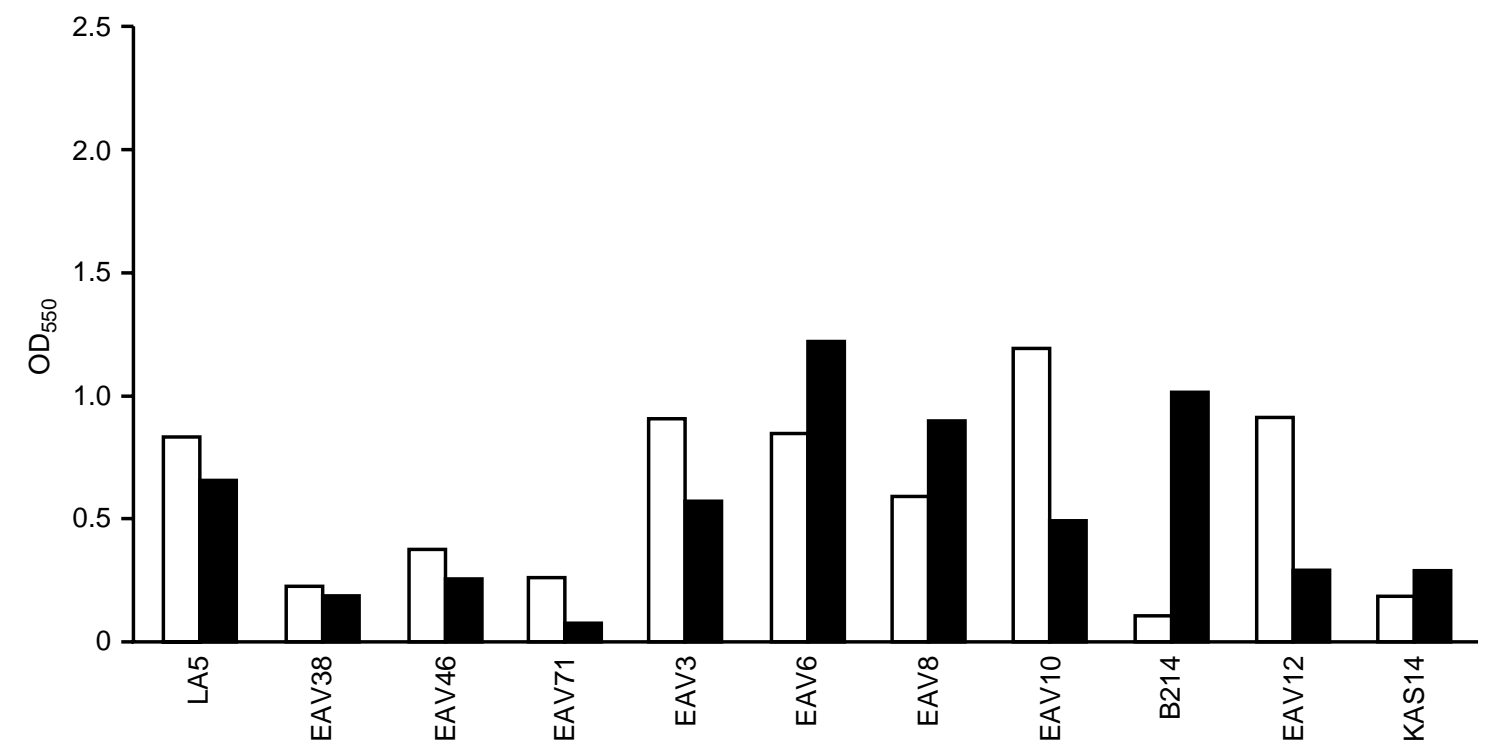

Fig. 1. Adherence of strain LA5 and isogenic non-fimbriate and non-flagellate mutant strains of Enteritidis to polystyrene. $\square, 37^{\circ} \mathrm{C} ; \mathbf{\square}, 25^{\circ} \mathrm{C}$. 


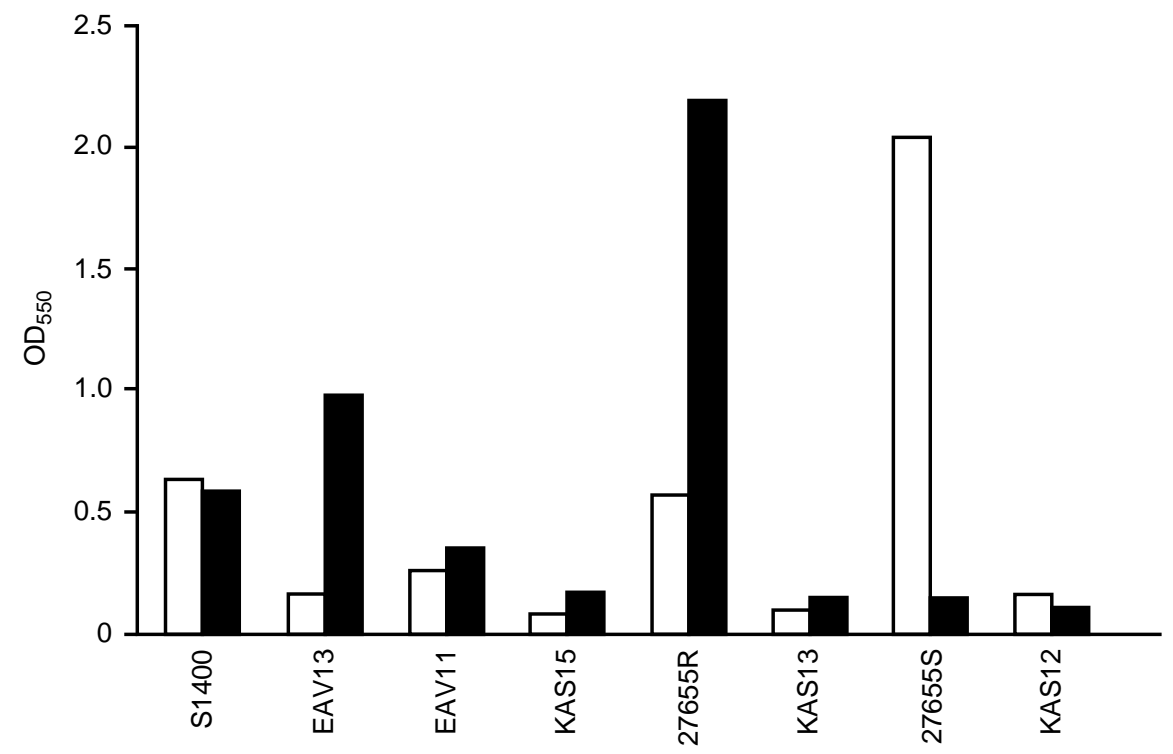

Fig. 2. Adherence of wild-type Enteritidis strains and isogenic SEF14 and SEF17 non-fimbriate mutant strains to polystyrene. $\square, 37^{\circ} \mathrm{C} ; \mathbf{\square}, 25^{\circ} \mathrm{C}$.

\section{Discussion}

Enteriditis strains adhere to inanimate surfaces such as vinyl and polystyrene when grown in CFA broth, a low osmotic, nutrient-poor medium known to support elaboration of SEF14 fimbriae at $37^{\circ} \mathrm{C}$ and SEF17 fimbriae at $25^{\circ} \mathrm{C}$ by Enteritidis [24-27]. Mutant strains of Enteritidis defective for the elaboration of SEF14 and SEF17 fimbriae showed reduced adherence in the order of $90 \%$ compared with the isogenic progenitor wild-type strains. Here was evidence that these fimbriae played a role in adherence to inanimate surfaces. However, adherence of SEF14 and SEF17 nonfimbriate mutants was not abolished and it was possible that these fimbriae were neither the sole nor the primary mechanism for adherence. SEF17 fimbriae are hydrophobic and mediate bacterial aggregation [29], whereas SEF14 fimbriae are elaborated upon contact with surfaces $[18,25,27]$. It is possible that the adherence demonstrated in the assays used in this study may be the result of bacterial aggregation after initial adherence to the surface.

HIB supports elaboration of SEF21 (type-1) fimbriae of Enteritidis [24], but was not associated with adherence, a finding in contrast to the report of Stenstrom and Kjelleberg [11]. These authors used radio-isotopically labelled bacterial cells prepared under various conditions in sensitive adherence assays to demonstrate that surface charge, to which the presence of type-1 fimbriae contributed, was a key factor in adherence. The differences in findings regarding type- 1 fimbriae may relate to the sensitivity of the assays. No role for PEF or LPF fimbriae in adherence was demonstrated, whereas motility most probably enhanced the opportunity for cell-to-cell contact, as suggested by others $[10,28,30]$.

Of the many serotypes of $S$. enterica, Enteritidis is unique in possessing the ability to elaborate SEF14 and SEF17 fimbriae, both of which contribute to adherence although under different environmental conditions. The ongoing epidemic of Enteritidis may relate in part to the success of the bacterium passing down the food chain with adherence to inanimate surfaces contributing to persistence as well as communicability. Enteritidis strains may adhere to surfaces such as eggs, foodprocessing equipment, animal carcasses and farm-yard implements over a wider range of environmental conditions than other Salmonella spp. Interestingly, Dhir and Dodd [31] showed that suspended and surface-attached Enteritidis were equally sensitive to biocide treatment. However, Austin et al. [12] suggested that SEF17 fimbriae present on adherent but killed bacteria on disinfected surfaces may act as sites for rapid recolonisation due to the aggregative properties of the fimbriae. It is noteworthy that strains $27655 \mathrm{R}$ and $27655 \mathrm{~S}$ were first described as possessing atypical surface properties and associated with persistence in a dry environment [32]. Also, recent reports have suggested that other novel surface structures were elaborated by Enteritidis which invaded and contaminated the surfaces of eggs [33-35]. The role of fimbriae and other surface antigens in environmental persistence and as potential targets for intervention strategies in the control of the current Enteritidis epidemic is worthy of further study.

The authors acknowledge the support and funding provided by the Department for Health, UK and Dr E. Allen-Vercoe for advice on strategies to construct multiple non-fimbriate Enteritidis mutant strains.

\section{References}

1. Schmidt K. WHO surveillance programme for control of foodborne infections and intoxications in Europe. Berlin, Federal Institute for Health Protection. 1995.

2. Rampling A, Anderson JR, Upson R, Peters E, Ward LR, 
Rowe B. Salmonella enteritidis phage type 4 infection of broiler chickens: a hazard to public health. Lancet 1989; 2: 436-438.

3. Morris GK, Wells JG. Salmonella contamination in a poultryprocessing plant. Appl Microbiol 1970; 19: 795-799.

4. Tadesse WM, Cizek A. The isolation of Salmonella from poultry carcasses and equipment in the poultry processing plant by the use of two procedures. Vet Med 1994; 39: 315-320.

5. Baier RE. Substrata influences on adhesion of microorganisms and their resultant new surface properties. In: Bitton G, Marshall KC (eds) Adsorption of microorganisms to surfaces. New York, John Wiley \& Sons. 1980: 59-104.

6. Rogers HJ. Adhesion of microorganisms to surfaces: some general considerations of the role of the envelope. In: Ellwood DC, Melling J, Rutter P (eds) Adhesion of microorganisms to surfaces. Society for General Microbiology special publication 2. London, Acadmic Press. 1979: 29-55.

7. Notermans S, Kampelmacher EH. Attachment of some bacterial strains to the skin of broiler chickens. $\mathrm{Br}$ Poultry Sci 1974; 15: 573-585.

8. Lillard HS. Role of fimbriae and flagella in attachment of Salmonella typhimurium to poultry skin. J Food Sci 1986; 51: 54-56.

9. Dickson JS, Koohmaraie M. Cell surface charge characteristics and their relationship to bacterial attachment to meat surfaces. Appl Environ Microbiol 1989; 55: 832-836.

10. Dickson JS, Daniels EK. Attachment of Salmonella typhimurium and Listeria monocytogenes to glass as affected by surface film thickness, cell density and bacterial motility. $J$ Indust Microbiol 1991; 8: 281-284.

11. Stenstrom T-A, Kjellberg S. Fimbriae mediated nonspecific adhesion of Salmonella typhimurium to mineral particles. Arch Microbiol 1985; 143: 6-10.

12. Austin JW, Sanders G, Kay WW, Collinson SK. Thin aggregative fimbriae enhance Salmonella enteritidis biofilm formation. FEMS Microbiol Lett 1998; 162: 295-301.

13. Solano C, Sesma B, Alvarez M, Humphrey TJ, Thorns CJ, Gamazo C. Discrimination of strains of Salmonella enteritidis with differing levels of virulence by an in vitro glass adherence test. J Clin Microbiol 1998; 36: 674-678.

14. Vidal O, Longin R, Prigent-Combert C, Dorel C, Hooreman M, Lejeune P. Isolation of an Escherichia coli K-12 mutant strain able to form biofilms on inert surfaces: involvement of a new ompR allele that increases curli expression. J Bacteriol 1998; 180: $2442-2449$

15. Lockman HA, Curtiss R. Virulence of non-type 1-fimbriated and nonfimbriated nonflagellated Salmonella typhimurium mutants in murine typhoid fever. Infect Immum 1992; 60: $491-496$.

16. Bäumler AJ, Tsolis RM, Heffron F. Contribution of fimbrial operons to attachment to and invasion of epithelial cell lines by Salmonella typhimurium. Infect Immun 1996; 64: $1862-1865$.

17. van der Velden AWM, Bäumler AJ, Tsolis RM, Heffron F. Multiple fimbrial adhesins are required for full virulence of Salmonella typhimurium in mice. Infect Immun 1998; 66: 2803-2808.

18. Thorns CJ, Sojka MG, Chasey D. Detection of a novel fimbrial structure on the surface of Salmonella enteritidis using a monoclonal antibody. J Clin Microbiol 1990; 28: 2409-2414.

19. Turcotte C, Woodward MJ. Cloning, DNA nucleotide sequence and distribution of the gene encoding the SEF14 fimbrial antigen of Salmonella enteritidis. J Gen Microbiol 1993; 139:
$1488-1485$

20. Clouthier SC, Müller K-H, Doran JL, Collinson SK, Kay WW. Characterization of three fimbrial genes, sefABC, of Salmonella enteritidis. J Bacteriol 1993; 175: 2523-2533.

21. Allen-Vercoe E, Woodward MJ. The role of flagella, but not fimbriae, in the adherence of Salmonella enterica serotype Enteritidis to chick gut explant. J Med Microbiol 1999; 48: $771-780$

22. Allen-Vercoe E, Sayers AR, Woodward MJ. Virulence of Salmonella enterica serotype Enteritidis aflagellate and afimbriate mutants in a day-old chick model. Epidemiol Infect 1999; 122: 395-402.

23. Thiagarajan D, Thacker HL, Saeed AM. Experimental infection of laying hens with Salmonella enteritidis that express differen types of fimbriae. Poult Sci 1996; 75: 1365-1372.

24. Sojka MG, Dibb-Fuller M, Thorns CJ. Characterisation of monoclonal antibodies specific to SEF 21 fimbriae of Salmonella enteritidis and their reactivity with other salmonellae and enterobacteria. Vet Microbiol 1996; 48: 207-221.

25. Thorns CJ, Sojka MG, Mclaren IM, Dibb-Fuller M. Characterisation of monoclonal antibodies against a fimbrial structure of Salmonella enteritidis and certain other serogroup D salmonellae and their application as serotyping reagents. Res Vet Sci 1992; 53: 300-308.

26. Dibb-Fuller M, Allen-Vercoe E, Woodward MJ, Thorns CJ. Expression of SEF17 fimbriae by Salmonella enteritidis. Lett Appl Microbiol 1997; 25: 447-452.

27. Walker SL, Sojka M, Dibb-Fuller M, Woodward MJ. Effect of $\mathrm{pH}$, temperature and surface contact on the elaboration of fimbriae and flagella by Salmonella serotype Enteritidis. J Med Microbiol 1999; 48: 253-261.

28. Pratt LA, Kolter R. Genetic analysis of Escherichia coli biofilm formation: roles of flagella, motility, chemotaxis and type 1 pili. Mol Microbiol 1998; 30: 285-293.

29. Collinson SK, Emödy L, Müller K-H, Trust TJ, Kay WW. Purification and characterization of thin, aggregative fimbriae from Salmonella enteritidis. J Bacteriol 1991; 173: 47734781 .

30. O'Toole GA, Kolter R. Flagellar and twitching motility are necessary for Pseudomonas aeruginosa biofilm development. Mol Microbiol 1998; 30 295-304.

31. Dhir VK, Dodd CER. Susceptibilty of suspended and surfaceattached Salmonella enteritidis to biocides and elevated temperatures. Appl Environ Microbiol 1995; 61: 1731-1738.

32. Baloda SB, Faris A, Krovacek K. Cell-surface properties of enterotoxigenic and cytotoxic Salmonella enteritidis and Salmonella typhimurium: studies on haemagglutination, cell surface hydrophobicity, attachment to human intestinal cells and fibronectin-binding. Microbiol Immunol 1988; 32: 447-459.

33. Guard-Petter J, Keller LH, Rahman MM, Carlson RW, Silvers $\mathrm{S}$. A novel relationship between $\mathrm{O}$-antigen variation, matrix formation, and invasiveness of Salmonella enteritidis. Epidemiol Infect 1996; 117: 219-231.

34. Petter JG. Detection of two smooth colony phenotypes in a Salmonella enteritidis isolate which vary in their ability to contaminate eggs. Appl Environ Microbiol 1993; 59: 28842890.

35. Guard-Petter J, Lakshmi B, Carlson R, Ingram K. Characterization of lipopolysaccharide heterogeneity in Salmonella enteritidis by an improved gel electrophoresis method. Appl Environ Microbiol 1995; 61: 2845-2851. 